\title{
Study on the Strategies of Vocabulary Teaching in College English
}

\author{
Xiu Zeng \\ Foreign Language Department, Nanchang Normal University \\ Postcode: 330029; 2267395464@qq.com
}

Keywords: Strategy; Vocabulary; Language teaching

\begin{abstract}
English vocabulary learning has long been viewed as a challenge to most Chinese students because of their weak language foundation, inability to learn words efficiently and less targeted practice of language in the communication in English. Much attention has been directed to the low efficiency in the acquisition and mastery of English vocabulary. By adopting some widely used vocabulary teaching approaches, this paper attempts to explore strategies to improve vocabulary learning and teaching in the whole process of language education.
\end{abstract}

\section{Introduction}

Vocabulary is one of the basic elements in any language acquisition and also an important foundation for both oral and written communication in social life. The size and choice of vocabulary is usually considered to be a sign of one's language competence. Vocabulary is more important than grammar in that grammar at least seems to be finite, while vocabulary is actually infinite. Words are more complex than they appear to be on the surface. Just as Wilkins holds 'without grammar, very little could be conveyed, while without vocabulary, nothing could be conveyed' [1].

For most Chinese learners, English learning is still a big problem. Even students at university level suffer from a limited lexicon and weakness in a free use of words though they work hard and do well in reading exam. Often they have difficulty expressing their ideas in proper English even when they are bursting with fountains of ideas. To get students out of the plight, to improve their language competence and efficiency of English teaching, here in this paper it is suggested that students be provided strategies to acquire English in more effective ways.

For majority of Chinese students, English is a second language that is taken as a compulsory course in both high school and university. In spite of the fact that much time and efforts have been devoted to the learning in their secondary school, they still cannot make proper use of English words to express themselves in university, therefore introduction of strategies may be needed.

Vocabulary is a necessary ingredient for all communication. Language learners encounter vocabulary on a daily basis, and must be able to acquire and retain it. As a language teacher, one of the main tasks is to help students develop a rich and useful vocabulary inventory.

\section{Strategies Suggested in the Process of English Teaching}

It is quite often found that vocabulary items are imparted mostly by translation: either a list of words with their translation at the beginning of the lesson or the translation of the content having new words or glossaries at the very end. This is an erroneous practice as it leads to a state of confusion for the learners. On the teaching skills of vocabulary items, Frisky (1957) commented that "While the teacher is not, himself, concerned with the actual selection of vocabulary for text book purposes since practically all the books we use are based on limited vocabularies, it is important that he/she (the teacher) should know the principles, which underlie vocabulary selection" [2]. Thus it means that a language teacher should be skillful in the application of methods pertaining to teaching vocabulary items in a classroom situation.

Research shows that there are more words to be learned than can be directly taught in even the 
most ambitious program of vocabulary instruction. Instruction in word-learning strategies gives students tools for independently determining the meanings of unfamiliar words that have not been explicitly introduced in class. Since students encounter many difficulties in their English vocabulary learning, any help provided by relevant strategies can be useful.

\section{Fostering Word Consciousness}

Word consciousness refers to an awareness that words are the building blocks of language and that they can be examined and manipulated (Scott, Wells, 2008)[3]. Creating an environment that builds word consciousness means that we prefer finding new words, figuring out what they mean, looking for multiple meanings, and adding them to our linguistic repertoire.

Word consciousness is not an isolated component of vocabulary instruction; it needs to be taken into account each and every day (Scott and Nagy, 2004)[3]. It can be developed at all times and in several ways: through encouraging adept diction, through word play, and through research on word origins or histories .According to Graves (2000), "If we can get students interested in playing with words and language, then we are at least halfway to the goal of creating the sort of word-conscious students who will make words a lifetime interest." [4].

Building word consciousness is powerful and fun. It is also an effective tool for vocabulary building. For more advanced language users, we can help them become more interested in the words they hear as they move throughout their daily lives. We can create a culture in which students pay attention to new words and develop a curiosity about what they mean and how they are used. It is an introductory step to the following language learning.

\section{Distinguishing Receptive and Productive Vocabulary}

An important consideration for teachers planning vocabulary work is to distinguish between receptive and productive vocabulary. We all understand many more words than we actually use in daily situation. Receptive vocabulary is the set of words that we recognize and understand, but tend not to use so often. At beginner level most new words learned by students have obvious immediate practical uses; they quickly become part of our everyday English that is productive vocabulary. It is important for an instructor to understand the differences and apply this specifically to vocabulary teaching. In order to know a word receptively, it is expected that the learner must:

- be able to recognize the word when it is heard;

- realize that the word is made up of different morphological parts and be able to relate these parts to its meaning;

- know the meaning of the word, and also know what the word means in the particular context in which it has occurred;

- Understand the concept behind the word in order to be able to understand it in a variety of contexts.

Similarly, productive knowledge implies that the learner must be able to

$\diamond$ properly pronounce the word;

$\diamond \quad$ write the word and spell it correctly;

$\diamond$ Produce the word to express its proper meaning and correctly use the word in an original sentence.

When we consider what it means to know a word, it becomes apparent why it is necessary to 
actively teach vocabulary and to recycle the same vocabulary item in multiple contexts.

\section{Providing Exposures to Contexts}

The scientific research on vocabulary instruction reveals that most vocabulary is acquired incidentally through indirect exposure to words. Students can acquire vocabulary incidentally by engaging in rich language experiences at home and at school. Students need to encounter vocabulary in various contexts in order to remember it and to develop an understanding of the range of usage of a given word. Linguistic researchers argue that vocabulary words must be repeated in different contexts because contexts-of-use are associated with different cognitive processes during language learning.

According to Stahl (2005), students probably have to see a word more than once to place it firmly in their long-term memories. "This does not mean mere repetition or drill of the word, but mean seeing the word in different and multiple contexts. "[4]. Kamil and Hiebert (2005) reason that extensive reading gives students repeated or multiple exposures to words and is also one of the means by which students see vocabulary in rich contexts [5].

For incidental vocabulary learning, context is important because texts are full of "clues" about the meanings of words. Other words in a sentence or paragraph, captions, illustrations and titles provide readers with information about the text that they can use to determine the meanings of unfamiliar words. These features are often referred to as "context clues" because they are contained within the context of the piece of writing rather than outside it. Readers should be taught to find and use context clues for learning new words. Modeling and practice are the key for helping students develop this important reading skill.

\section{Organizing Activities for Listening Practice}

Careful listening to the words may be a good option in teaching vocabulary items in a classroom. "Let the students hear the word in isolation and in a sentence. If the sounds of the words have been mastered, the students will hear it correctly with two or three repetitions." (Robert Lado: 121) [6].

Listening activities, if organized well, can help students review the previously-learned words and consolidate newly-learned ones, for the same or related theme in each unit of a textbook goes through every part of the unit with many synonyms repeated and related ideas developed. Further progress can be made by trying paralleled text, modified versions of the text with different details. Besides course-book CD and cassette, other listening materials can also be introduced to students after class to familiarize them with a variety of words. Such a constant exposure to different language materials can improve students' listening comprehension on the one hand, and facilitate students' effective assimilation of new language into their existing cognitive structure on the other hand.

\section{Taking Review and Reinforcement}

It is common sense that the more times we are exposed to a word, the stronger our understanding of words becomes. However, the fact is often neglected that students do not learn from the first presentation of the new words. They need to be introduced or even reintroduced to the new items until they can have a full command of what they have learnt and produce them automatically when required[7].

To reach this goal, students are often asked to practice a certain number of language models, sentence patterns or simply word substitution. Almost in any English textbooks, there is always such an item of exercise "rewrite the following sentences after the models" or "replace A with B", etc. The repeated phrases and structures are usually the most often used and idiomatic ones. Providing students with multiple opportunities to use a new word in its written and spoken forms helps them solidify their understanding of words. 
There are two major types of written exercises divided as "vocabulary" and "grammar" in each reading unit. Translation exercise is included in "vocabulary" item. To translate sentences into English is intended to practice certain target words and sentence structures that appear in the text. It is more difficult than simply filling in blanks, or replacement of words, for it is a test on one's understanding of the words and correct use of grammatical patterns, it can promote a free use of language in later task of composition though there is no sense of communication, no sense of authenticity in it.

\section{Analyzing Word Formation}

While root analysis is taught explicitly, the ultimate goal is for readers to use this strategy independently. Many of the words in English language are derived from Latin or Greek roots. They either contain a "core" root or use prefixes or suffixes that hold meaning. Teachers should focus on teaching students the most commonly occurring roots, prefixes and suffixes, for each word is a taught example of its use in common words. Reader should see how the root helps them understand the word's definition. Students should then be given practice of analyzing words to determine their roots and definitions. When a reader is able to break down unfamiliar words into prefixes, suffixes and roots, they can begin to determine their meanings.

Some of prefixes, suffixes and roots can help form synonyms and antonyms . One excellent technique of improving vocabulary is to learn synonyms and antonyms together. Teachers can create a chart listing both synonyms and antonyms including example sentences to help students memorize new vocabulary. Synonyms and antonyms can be learned in categories such as adjectives, adverbs, and adverbs. It's a good habit to begin building vocabulary by learning categories of English synonyms and antonyms.

With the help of word formation, both synonyms and antonyms may be used to help the student to understand the different shades of meaning if the synonym or the antonym is better known than the word being taught. Further, only if students master the word-formation principle, they will be able to produce new words. Teachers can design different kinds of exercises to help students be familiar with the word-building rules. Synonyms and antonyms help to enrich a student's vocabulary bank and provide alternative words instantly.

\section{Conclusion}

To sum up, word learning is a long, complex and creative process in which a series of language skill practice and the related activities are involved and interrelated [8]. An efficient language teacher can use selected vocabulary activities or can use integrated activities. All this depends upon ability and level of understanding and interest of the learners. There is no sure remedy or method to enhance vocabulary in a day or two. A student's vocabulary bank can be enriched on a gradual basis and one should always show keen interest and enthusiasm in finding, learning and understanding new words.

Therefore, we can say that practice of language skill helps bring about an increase in the efficiency of word study on the one hand, an improvement in word learning ability contributes much to the development of language skills on the other hand [9]. Vocabulary learning, like the practice of language skills, is a part of language acquisition and a part of quality-oriented education. If a teacher of English has a deep understanding of the interrelation between vocabulary learning and the contributing factors, then all the efforts made by teachers and students will be much rewarded.

\section{References}

[1] Wilkins,D.A. National Syllabuses Oxford: OUP, 1976. 
[2] A.W. Frisby (1957), "Teaching English", The English Language Book Society and Longmans Green and Co., p.98.

[3] Scott, J. Skobel, B., \& Wells, J. (2008). The Word Conscious Classroom: Building the Vocabulary Reader and Writers Need. NY: Scholastic.

[4] Linda Diamond, Linda Gutlohn. (2006). Vocabulary Handbook: Teaching Vocabulary. Brookes Publishing Co.

[5] Kamil, M. L., \& Hiebert, E. (2005). Vocabulary: Making the Connections in Research. In E. Hiebert \& M. L. Kamil (Eds.) Teaching and Learning Vocabulary (pp. 1-23). Mahwah, NJ: Erlbaum.

[6] Robert Lado (1964), "Language Teaching: A Scientific Approach", McGraw Hill: New York, p.121.

[7] Paul Davies.(2002). Success In English Teaching [M]. Shanghai: Shanghai Foreign Language Education.

[8] L.M. Yang: New College English (Shanghai Foreign Language Education Press, 2002).

[9] Q.S. Chen: Teaching English in China, 2005, No.4, p.107-110. 